\title{
UMA COSMOVISÃO DO DESENVOLVIMENTO SUSTENTÁVEL
}

\section{A COSMOVISION OF SUSTAINABLE DEVELOPMENT}

\author{
1João Ricardo Vicente \\ ${ }^{2}$ Kamylla da Silva Bezerra
}

\section{RESUMO}

O direito e as relações globais trazem para a ribalta temas como sistema democrático, liberdades e direitos humanos, como desvelam promessas não cumpridas pela modernidade, tal qual a persistência da pobreza e privações diversas mesmo em países ricos. O enfrentamento de tais problemas constitui parte do desenvolvimento sustentável, sendo curial salientar o papel das liberdades individuais, ainda quando limitadas na seara das oportunidades sociais, econômicas e políticas. Este artigo objetiva realizar uma analise diagnóstica sobre projeções de novas formas de articulação política e jurídica entre os atores sociais na busca da construção do Estado Democrático de Direito.

Palavras-Chave: Sustentabilidade; desenvolvimento; liberdade; políticas públicas; democracia.

\begin{abstract}
The law and the global relations bring to the stage themes as democratic system, liberties and human rights, as disclose incompleted promises by modernity, such as poverty persistence and different privations even in rich countries. The facing of such problems build part of the sustainable development, being crucial emphasizes the role of the individual liberties, even when limited in the area of social, economic and political opportunities. This article aims to accomplish a diagnostic analysis over projections from new ways of political and juridical arrangements among the social actors in the search for Democratic Law State construction.
\end{abstract}

Keywords: Sustainability; development; liberty; public policies; democracy.

\footnotetext{
${ }^{1}$ Mestrando em Direito e Políticas Públicas pela Universidade Federal do Estado do Rio de Janeiro - UNIRIO, Rio de Janeiro (Brasil). E-mail: jricvic@yahoo.com.br

${ }^{2}$ Mestranda em Direito e Políticas Públicas pela Universidade Federal do Estado do Rio de Janeiro - UNIRIO, Rio de Janeiro (Brasil). E-mail: kamyllabezerra_@ @hotmail.com
} 


\section{INTRODUÇÃO}

A consolidação da sustentabilidade como um dos objetivos das contratações públicas no Brasil, não ocorreu unicamente pela nova regra normativa trazida com o advento do Decreto 7746.12 (que regulamentou o art. $3^{\circ}$ da Lei 8666.93), mas sobretudo porque o tema se consagrou pelos objetivos humanistas que representa e cujas fronteiras não coincidem com os limites geográficos domésticos.

A reinvenção da noção do critério mais vantajoso em prol do bem estar social a reverberar numa ideologia de que as contratações públicas sejam utilizadas também para se construir espaços sustentavelmente humanizados e despertar um consumo consciente e comprometido com as gerações presentes e futuras não floresceu em solo brasileiro de forma descolada da política internacional. Assim, para que o jurista compreenda as licitações sustentáveis sob a ótica de um mundo globalizado, se faz necessário compreender o Direito como vetor de mudanças substantivas e estruturais, além de receptor de pressões políticas, econômicas e sociais e, precipuamente, como componente de um mundo que se transforma e a nós se impõe (SANTANA, 2015, p. 44).

Por outro lado, o direito ao desenvolvimento como direito humano inalienável foi estabelecido pela Declaração sobre o direito ao desenvolvimento, adotada pela Resolução no 41/128 da Assembleia Geral das Nações Unidas, de 4.12.1986, sendo o sujeito central a pessoa humana. Foi prescrito para cada Estado o dever de formular políticas nacionais adequadas ao desenvolvimento e visando aprimorar constantemente o bem estar populacional e individual, baseado na sua participação ativa, livre e significativa, mormente através da adoção de medidas assecuratórias do exercício pleno e progressivo fortalecimento do direito ao desenvolvimento, o que congloba formulação, adoção e implementação de políticas, medidas legislativas e outras, em níveis internacional e doméstico.

Outrossim, no que tange ao direito a um meio ambiente sadio figura na esfera de proteção internacional dos direitos humanos, expressamente plasmado no Protocolo adicional à Convenção Americana sobre Direitos Humanos em Matérias de Direitos Econômicos, Sociais e Culturais Protocolo de San Salvador (1988), ratificado pela República Federativa do Brasil em 21 de agosto de 1996. 
Por sua vez, a Declaração de Viena e programa de ação, perfilhada em 25.6 .1993 pela Conferência Mundial sobre os Direitos do Homem serviu para consolidar o entendimento sobre a indivisibilidade e interdependência dos Direitos Humanos presente na Declaração sobre o direito ao desenvolvimento. Dessa forma, encontram-se amalgamados os direitos ao desenvolvimento e ao meio ambiente, incumbindo aos Estados considerá-los conjuntamente nas políticas nacionais e internacionais que perfilharem.

As remissões acima remetem ao Relatório Bruntland (1987) da Comissão Mundial sobre Meio Ambiente e Desenvolvimento (ONU) e ao Capítulo 3 da Agenda 21 na Rio 92 com referência explícita da relação entre erradicação da pobreza e desenvolvimento sustentável. Mesmo quando não diretamente incorporados, os compromissos internacionais norteiam os Estados nacionais na implementação de políticas públicas voltadas para o desenvolvimento e licitações sustentáveis.

Dessa forma, a Política Nacional do Meio Ambiente (Lei 6938.81) adveio após a Declaração da Conferência das Nações Unidas sobre o meio ambiente (Estocolmo - 1972) trazendo como um de seus objetivos o desenvolvimento econômico e social compatível com a preservação ambiental. Ainda, o próprio preâmbulo da Declaração de Estocolmo serviu para influenciar o Estatuto das Cidades (Lei 10257.01) reverberando na previsão de expansão urbana compatível com os limites da sustentabilidade ambiental, social e econômica da localidade.

A Declaração do Rio sobre Meio Ambiente e Desenvolvimento (1992) embora despida da validade formal de um tratado, pois não houve o recolhimento de assinaturas e tampouco abertura para ratificação ou adesão, consubstanciou um documento relevante como declaração de princípios, em continuidade à Declaração de Estocolmo (1972), especificamente influenciadora das contratações públicas sustentáveis pelo Princípio 8: Para alcançar o desenvolvimento sustentável e uma qualidade de vida mais elevada para todos, os Estados devem reduzir e eliminar os padrões insustentáveis de produção e consumo, e promover políticas demográficas adequadas.

Na Conferência Rio 92, também foi assinada a Agenda 21 Global, cujo capítulo 4, (malgrado num contexto referente a instrumentos de planejamento para a construção de cidades sustentáveis conciliadoras de proteção ambiental, eficiência econômica e justiça social) acabou prevendo tópico específico referente às licitações sustentáveis intitulado Mudanças nos padrões de consumo.

Nesta Agenda 21 Global destacam-se duas áreas programáticas: exame dos insustentáveis padrões de produção e consumo e desenvolvimento de políticas nacionais estratégicas para 
estimular mudanças nos padrões insustentáveis de consumo. Além da prioridade alta no primeiro caso, no segundo requer-se ainda o fomento de um público consumidor informado, suficientemente capaz de fazer opções ambientalmente adequadas, em que recrudesce a responsabilidade estatal exemplar no exercício da liderança através da conformação do objeto das aquisições públicas. Quanto ao exame dos padrões de consumo e pressão ambiental sobre a produção, bem como descarte final adequado dos resíduos, restaram todos contemplados na Política Nacional de Resíduos Sólidos - Lei 12.305.10.

Registre-se, ainda com foco nas licitações sustentáveis, que também foi assinada durante a Conferência das Nações Unidas sobre Meio Ambiente e Desenvolvimento a Convenção sobre diversidade biológica (1992), vindo a ser promulgada no Brasil pelo Decreto 2519.98, sendo que a previsão na Agenda 21 da adoção de estratégias nacionais de desenvolvimento sustentável refletiu numa Agenda 21 brasileira constante do Anexo II do Plano Plurianual 2008.2011 - Lei 11653.08, que incorporou dito programa de governo.

Por fim, a Convenção-Quadro das Nações Unidas sobre mudança do clima (1992) pode ser destacada como importante instrumento do Direito Internacional Público, promulgada no Brasil via Decreto 2652.98, a refletir em âmbito doméstico na Lei 12187.09 - Política Nacional sobre Mudança do Clima.

Nesse sentido esse trabalho tem por objetivo realizar uma analise diagnóstica sobre problemáticas e projeções de novas formas de articulação política e jurídica entre os atores sociais em busca da construção do Estado Democrático de Direito, através da reflexão interdisciplinar sobre: Pós-modernidade, globalização e universalização dos direitos humanos e sua repercussão na modificação fática e compreensiva das realidades social, econômica e jurídica.

\section{A3P E A POLÍTICA NACIONAL DO MEIO AMBIENTE}

A Política Nacional do Meio Ambiente foi criada com o advento da Lei $\mathrm{n}^{\circ}$ 6.938.81, marco legal que incorporou normativamente diversos temas: meio ambiente, degradação da qualidade ambiental, poluição, poluidor, recursos ambientais, além de instituir mecanismos de proteção ambiental, a exemplo do estudo prévio de impacto ambiental (EIA) e respectivo relatório (RIMA), hodiernos instrumentos em termos ambientais mundiais. 
No nível global, a Conferência da ONU sobre o Meio Ambiente e Desenvolvimento, realizada no Rio de Janeiro e conhecida como ECO-92, sacramentou a preocupação com as questões ambientais, reforçando princípios e regras para o combate à degradação ambiental. Da Conferência nasceu a Agenda 21, instrumento diretriz do desenvolvimento sustentável que harmoniza métodos de proteção ambiental, justiça social e eficiência econômica.

Em 1999, a Agenda Ambiental na Administração Pública (A3P) exsurgiu como um projeto do Ministério do Meio Ambiente a fim de revisar padrões de produção e consumo e adotar referenciais pra sustentabilidade ambiental em instituições da administração pública.

Lançado o projeto, foi criado o Programa Agenda Ambiental na Administração Pública, cujo objetivo era sensibilizar gestores públicos para a importância de questões ambientais, estimulando-os a incorporar os princípios e os critérios de gestão ambiental em suas atividades rotineiras.

Os fundamentos das diretrizes da A3P se encontram nas recomendações do Capítulo IV da Agenda 21, indicador aos países do "estabelecimento de programas voltados ao exame dos padrões insustentáveis de produção e consumo e o desenvolvimento de políticas e estratégias nacionais de estímulo a mudanças nos padrões insustentáveis de consumo", e no Princípio 8 da Declaração do Rio/92: "os Estados devem reduzir e eliminar padrões insustentáveis de produção e consumo e promover políticas demográficas adequadas".

Em 2002, a A3P foi laureada pela Unesco pelo trabalho relevante desempenhado e resultados positivos obtidos ao longo do seu desenvolvimento, ganhando o prêmio "O melhor dos exemplos" na categoria Meio Ambiente.

Para garantia dos recursos que viabilizaram sua implantação efetiva, a A3P foi incluída no PPA 2004/2007 (e continuada no PPA 2008/2011) como ação integrante do programa de Educação Ambiental para Sociedades Sustentáveis.

Depois de 2007, com a reestruturação do Ministério do Meio Ambiente, a A3P passou a integrar o Departamento de Cidadania e Responsabilidade Socioambiental (DCRS), da Secretaria de Articulação Institucional e Cidadania Ambiental (SAIC). Nesse novo arranjo institucional, a A3P se fortaleceu como Agenda de Responsabilidade Socioambiental do Governo, passando a ser 
uma das principais ações para proposição e estabelecimento de um novo compromisso governamental diante das atividades da gestão pública, conglobando critérios ambientais, econômicos e sociais a tais atividades.

Hodiernamente, o maior desafio da A3P consiste na promoção da Responsabilidade Socioambiental como política governamental, auxiliando na integração da agenda de crescimento econômico simultaneamente ao desenvolvimento sustentável, por via da inserção de princípios e práticas de sustentabilidade socioambiental no âmbito da administração pública.

Vale ressaltar que no setor empresarial, a responsabilidade social das empresas reflete um conceito revelador da decisão de contribuir voluntariamente em prol de uma sociedade melhor e de um ambiente equilibrado e sadio. Os compromissos assumidos de voluntariamente pelas empresas transcendem as obrigações legais, regulamentares e convencionais que devem ser cumpridas de forma cogente. As empresas que optam por investir em práticas de responsabilidade social elevam os níveis de desenvolvimento social, proteção ao meio ambiente e respeito aos direitos humanos e perfilham um modo de governança aberto e transparente que concilia interesses de diversos agentes em um enfoque global de qualidade e viabilidade.

Conquanto programa a incorporar os princípios da responsabilidade socioambiental nas atividades da Administração Pública, a A3P fomenta ações embasadoras e estruturadoras em seus quatro eixos temáticos: compras e serviços sustentáveis, sensibilização e capacitação dos servidores, qualidade de vida no ambiente de trabalho e gestão adequada dos recursos utilizados e resíduos gerados.

\section{HORIZONTES ENTRE LIBERDADE E DESENVOLVIMENTO SUSTENTÁVEL}

Se concebida como compromisso social, a expansão da liberdade individual constitui fim e meio do desenvolvimento, que se instrumentaliza tanto no aspecto social (via serviços) como econômico (das oportunidades) e político (das liberdades), donde recrudesce a importância das instituições na qualidade de transformadoras dos indivíduos receptores de prestações em agentes de mudanças através de políticas econômicas e sociais fomentadas por debates públicos veiculadores dos câmbios sociais. 
Ao invés de identificado com o crescimento do produto interno bruto, aumento das rendas pessoais, industrialização, avanços tecnológicos ou modernização social, o desenvolvimento pode também ser concebido como um processo integrado de expansão das liberdades individualmente desfrutadas.

Além das determinantes supracitadas, os direitos humanos e políticos, bem como as instituições sociais e econômicas, contribuem de maneira vital para a expansão das liberdades fundamentais.

No entanto, a vitória do desenvolvimento exige a erradicação de vários inimigos: pobreza e tirania, escassez de oportunidades econômicas e privações sociais sistemáticas, abandono dos serviços públicos e intolerância ou excesso de intervenção estatal repressiva.

O progresso somente pode ser valorado em função do aumento da liberdade dos indivíduos, enquanto a eficácia do desenvolvimento depende da liberdade de suas agendas, particularmente aferível nas interconexões entre os diversos tipos de liberdades que se reforçam reciprocamente, até constituir um motor do desenvolvimento.

Os mecanismos institucionais para aproveitamento das liberdades individuais também dependem do exercício das liberdades de participar nas decisões sociais e na elaboração das decisões públicas que impulsionam o progresso das oportunidades, porquanto componentes constitutivos do desenvolvimento.

Um exemplo da relevância da concepção da liberdade como finalidade do desenvolvimento pode ser visto sobre o papel desempenhado pelos mercados no processo de desenvolvimento, na medida em que o intercâmbio de bens faz parte do modo humano de viver e de se inter-relacionar em sociedade.

Por outro lado, a denegação da liberdade para participar no mercado de trabalho consiste em uma das maneiras de manter os indivíduos como cativos ou escravos, sendo um dos desafios fundamentais do desenvolvimento a necessidade de liberar o trabalho dos grilhões que negam acesso ao mercado de trabalho aberto. Dessa forma, a negação de acesso aos mercados de produtos constitui uma das privações que sofrem os pequenos empresários por causa de sistemas e restrições tradicionais, sem olvidar que a liberdade para realizar intercâmbios econômicos desempenha um papel essencial na vida social.

Embora seja difícil imaginar um processo de desenvolvimento muito descolado dos mercados, a vida humana pode ser enriquecida também através do papel da legislação, da 
intervenção estatal e de ajuda social, e de instituições como partidos políticos, sistemas de educação e as oportunidades de diálogo e debates públicos.

Ao encontro do clamor de acesso aos mercados pelo pequeno empresariado, o direito brasileiro contribuiu com recentes alterações normativas na seara das licitações rumo à efetivação dos objetivos fundamentais do Estado brasileiro consubstanciados na redução das desigualdades sociais e da erradicação da pobreza e da marginalização.

Com o advento da Lei Complementar 123/06 (alterada em pela LC 147/2014), houve uma mudança no foco das contratações públicas: se antes traduziam seu objetivo de obter proposta mais vantajosa pelo prisma exclusivo do melhor preço, agora a licitação se transformou em instrumento de promoção de objetivos sociais, ao impulsionar desenvolvimento local e geração de emprego e renda na implementação do tratamento diferenciado aos pequenos empresários.

Essa política de viés redistributivo, através do direcionamento das licitações aos pequenos fornecedores, induz a gênese de arranjos locais, mormente em áreas de pouco desenvolvimento econômico, ampliando o conceito de vantajosidade para a sociedade.

Com o objetivo de ampliar a eficiência das políticas públicas, incentivar a inovação tecnológica e promover o desenvolvimento econômico e social no âmbito local e regional foi editado o Decreto 8.538, de 6 de outubro de 2015, que regulamentou o tratamento favorecido, diferenciado e simplificado para as microempresas, empresas de pequeno porte, agricultores familiares, produtores rurais pessoa física, microempreendedores individuais e sociedades cooperativas de consumo nas contratações públicas de bens, serviços e obras no âmbito da administração pública federal.

Agora, os órgãos e as entidades contratantes deverão realizar processo licitatório destinado exclusivamente à participação de microempresas e empresas de pequeno porte nos itens ou lotes de licitação cujo valor seja de até $\mathrm{R} \$ 80.000,00$ (oitenta mil reais).

Além disso, nas licitações para a aquisição de bens de natureza divisível, e desde que não haja prejuízos para o conjunto ou o complexo do objeto, os órgãos e as entidades contratantes deverão reservar cota de até vinte e cinco por cento do objeto para a contratação de microempresas e empresas de pequeno porte.

Assim a reserva de cotas abre uma janela aos desprovidos de condições econômicas para competir (no critério menor preço) com os grandes fornecedores, únicos detentores dos meios de produção em escala. 


\section{FECHANDO ENTENDIMENTOS}

O reducionismo, enquanto enfoque que tende a explicar a realidade social através de uma de suas partes, numa perspectiva sociológica oposta ao conceito de totalidade, nos permite compreender que a dicotomia entre nações em desenvolvimento e desenvolvidas pressupõe uma lei de necessidade histórica (metafísico princípio) que compele cada sociedade a buscar alcançar o estágio atual das chamadas sociedades modernizadas.

Uma rigidez normativa refratária das condições próprias de modernização de uma sociedade, aliada ao referencial de que a modernidade paradigmática se encontra alhures, dissimula a miopia na projeção da imagem de futuro ideal. Por outro lado, um processo social resultaria de uma tensão dialética permanente entre liberdade e determinismo, na medida em que cada situação concreta mensura a prevalência na combinação desses dois fatores de interação em favor de um modelo de possibilidades, pois tanto a liberdade é inconcebível sem limitações objetivas (niilismo), quanto o determinismo é inconcebível sem liberdade, eis que se converteria em fatalismo.

Assim, um modelo de possibilidade alberga a liberdade no gerúndio (se formando) ainda que intermitente, mas ao revés do determinismo necessário. A própria ciência social não seria científica se interpretasse fatos consumados como necessários ao invés de possíveis. Dessa forma, a possibilidade se configura como condição necessária a fim de que a realidade social seja objeto de análise científica, senão o cientista se tornaria um especialista em interpretações tautológicas post hoc.

Acreditar num processo unilinear de evolução ou crer num caminho único a ser palmilhado rumo ao futuro, como se fosse indispensável cumprir os preceitos de um ritual emancipatório compulsório, constitui um impedimento para que o potencial de inovação e criatividade encontre outros padrões conceituais mais apropriados. Ao mesmo tempo, atrelar ao desenvolvimento a necessidade de realização pessoal revelaria uma distinção entre as sociedades quanto ao grau de sensibilidade pela realização das pessoas. Destarte, seria o mundo, que hodiernamente apresenta características de um sistema onde todas as sociedades estão em desenvolvimento, a categoria cardinal das ciências sociais.

As liberdades de escolha são uma constante antropológica na interação com fatores objetivos para a produção dos acontecimentos, sendo as restrições contextuais limitadoras da 
compreensão da realidade, mediante uma dialética de participação e retraimento, pendular entre o abstrato e o concreto, cuja unidade (entre a teoria e a prática) compreende precipuamente o contextualismo dialético onde o sentido de uma ideia se opera nos câmbios que ela efetua nos objetos, como nossas atitudes.

Se a modernização constitui um subproduto do processo criador de uma sociedade planetária, logo toda sociedade seria penetrada pelo supersistema mundial cujo funcionamento efetivo ocorre a partir de condições como mercado internacional e redes de comunicação e transporte.

Nesse sentido, o tipo de consumo encontrado nas nações desenvolvidas, no efeito demonstração, serve para moldar o conjunto de aspirações das nações em desenvolvimento, deixando para trás a lúgubre ciência da economia tradicional: "A partir do "efeito demonstração" emergem padrões de ética mundial segundo os quais a pobreza se torna intolerável neste momento da história mundial em que existem recursos para eliminá-la. As pessoas começaram a se dar conta cada vez mais de que a erradicação da pobreza é impedida menos pela escassez de recursos materiais do que pelas restrições institucionais, em todo o mundo. Assim, como já foi salientado, a partir da perspectiva de uma ética mundial emergente, a opulência das sociedades hegemônicas torna-se imoral e impraticável. Os custos econômicos e psicológicos do atual sistema mundial, com áreas restritas de abundância em meio a áreas maiores de fome ou pobreza, tendem a aumentar geometricamente para as nações hegemônicas. (HEIDEMANN, 2014, p. 75)”.

Outro insurgente de sociedade planetária (relacionado com a modernização), o chamado efeito de dominação aflora como explicação da dinâmica das assimétricas relações entre as nações hegemônicas e as demais, decorrente das desiguais capacidades econômicas que sujeitam as nações submissas a adaptar-se a dito efeito.

Nesse sentido, o caráter reducionista da ideologia da modernidade deve ser combatido por uma nova antropologia, revisora das bases epistemológicas do pensamento moderno, reconhecedora da condição humana em cada pessoa e sociedade, bem como superadora da subordinação da proposta teórica das ciências sociais exclusivamente a um tipo de racionalidade (formal ou funcional).

A liberdade de consciência fomenta a emancipação dos pequenos contra o império do fatalismo. Consciência não se realiza somente pelo exercício da razão, mas pela capacidade humana de resistir a ser totalmente definido pela história. Caso contrário a consciência 
psicologizada traduziria mero produto desse determinismo ou falso universalismo de uma construção artificial e abstrata da razão. Não se deve olvidar que a liberdade criadora de possibilidades pode destruir o impossível.

Assim, é possível visualizar que a consciência do condicionamento da política pública pela política traz ao embate os limites e possibilidades de seu controle. Sendo latente que a efetividade dos direitos fundamentais reverbera em prol da questão social, a judicialização da política pode sedimentar uma arena para avanço da agenda igualitária, mormente em tempos de crise de representação e outras patologias próprias ao sistema da política, que contribuem para macular as estratégias de ação do Estado.

Optar por essa vereda pode insuflar a vertente do ativismo judiciário, cujos limites e possibidades de ação requentam debates acerca da separação das funções de poder, inaptidão funcional do órgãos jurisdicionais (eis que desprovidos de uma perspectiva de planejamento e eficiência) para uma ação corretiva ou até substitutiva no âmbito das políticas públicas, sem descurar do alcance da efetividade dos instrumentos disponíveis e da representatividade adequada na articulação das demandas. Outrossim, já existem pertinentes amostras apreciadas pelas cortes brasileiras:

Nesse sentido, o Tribunal de Contas da União - no julgamento do acórdão TC 020.253/2007-0 referente à Representação formulada por licitante, apresentando questionamento a respeito da Lei Complementar 123/2006, mencionou que, entre os vários aspectos inovadores da lei, estava o tratamento diferenciado e favorecido a ser dispensado às microempresas e empresas de pequeno porte no âmbito dos Poderes da União, dos Estados, do Distrito Federal e dos Municípios, no que se refere ao acesso ao mercado, inclusive quanto à preferência nas aquisições de bens e serviços pelos Poderes.

$\mathrm{Na}$ oportunidade, defendeu-se que a lei vinha com o intento bastante positivo, materializando, efetivamente, o princípio do "tratamento favorecido" às microempresas e empresas de pequeno porte, conforme previsão do artigo 170, inciso IX, da Constituição Federal. Seguiu-se o entendimento de que as exceções mencionadas não conflitam com o princípio da isonomia, uma vez que o art. $5^{\circ}$ da Constituição somente assegura igualdade entre os brasileiros e estrangeiros em matéria de direitos fundamentais, outrossim, o tratamento diferenciado resulta da própria situação de desigualdade dessas empresas em relação a outras que não têm a mesma natureza, sendo necessário tratar desigualmente os desiguais. 
Alhures, o plenário do Supremo Tribunal Federal - STF, ao apreciar a Ação Direta de Inconstitucionalidade - ADI 3070, delineou a possibilidade de a lei distinguir situações sem violar o princípio da igualdade e julgou procedente o pedido formulado pelo Procurador-Geral da República para declarar a inconstitucionalidade do $\S 4^{\circ}$ do art. 111 da Constituição do Estado do Rio Grande do Norte, que dispõe que, na análise de licitações, para averiguação da proposta mais vantajosa, são considerados, entre outros itens, os valores relativos aos impostos pagos à Fazenda Pública estadual. Entendeu-se que o dispositivo impugnado faz distinção entre brasileiros, o que afronta o disposto no art. 19, III, da CF, que veda à União, aos Estados, ao DF e aos Municípios criar distinções entre brasileiros ou preferências entre si. Considerou-se, também, na linha do julgamento acima relatado, que o preceito viola o princípio da isonomia, haja vista que assegura injustificada vantagem sobre os licitantes que não sejam contribuintes no Estado ou os que, sendoo, recolham menos impostos do que o licitante que pague mais, salientando que a ponderação ou consideração dos valores atinentes aos impostos pagos pelo licitante também não surge da natureza das coisas, nem é concretamente compreensível.

\section{CONSIDERAÇÕES FINAIS}

A cada ano recrudesce a importância da sustentabilidade porque faz consolidar um dos objetivos das contratações públicas no Brasil, sobretudo pelo fato de que a atividade legiferante sistematicamente amplia as implicações sustentáveis nas licitações e contratações públicas.

A atualização de novos normativos sobre os instrumentos aplicáveis às licitações aumentaram sua operacionalidade e utilidade como guia prático dos gestores públicos que pretendem nelas inserir critérios socioambientais, mormente revisitando o ser mais vantajoso em favor do bem estar da sociedade.

O fomento de um consumo consciente a partir das licitações sustentáveis como política pública tende a reforçar a preservação dos recursos naturais e desenvolvimento das potencialidades sociais e econômicas em âmbitos determinados.

O conceito de sustentabilidade transcende um entendimento que pode perpassar visões, percepções e compreensões distintas, mas cujas divergências servem para tornar mais rico o debate acerca de seu conteúdo semântico.

A princípio, os operadores do direito tomam contato com o tema pela via normativa, que o galvaniza como adjetivo do substantivo desenvolvimento, seu pressuposto. 
Todavia há outras lentes, notadamente de outras áreas do conhecimento, que permitem vislumbrar o fenômeno com base em outros alicerces, reestruturantes da construção do saber, inclusive considerando que a plataforma de desenvolvimento não se constituiria como condição necessária para o alcance da sustentabilidade.

Como num arranjo caleidoscópico, torna-se realmente possível compatibilizar o desenvolvimento econômico nacional com as questões distributivas sem deixar em segundo plano as liberdades sociais e individuais, porquanto não seria disjuntiva a lógica dos objetivos fundamentais republicanos.

Os influxos decorrentes da globalização serviram para intensificar o intercâmbio de dados e pluralidade de parâmetros. Destarte, para lograr êxito, a modernização requer um ajustamento ativo, papel decisivo exercido pelo governo no processo de mudança social e econômica.

Embora se questione o tamanho estatal adequado ao atingimento das promessas positivadas, é incontroverso que a indumentária constitucional brasileira veste um modelo mais social do que liberal, bastando para tal comprovação aferir a ideologia que desfila pelo rol do art. $3^{\circ}$ de nossa Carta Magna.

A evolução segue caminhos intermitentes em direção ao infinito de possibidades, desafiando cautela ao peregrino epistemológico, que deve fortalecer seu espírito para não sucumbir ao primeiro proselitismo que o defrontar.

Ser humano deve significar também fazer escolhas melhores e o refúgio da sabedoria auferida pode guardar o melhor diapasão, quiçá poeticamente, para que não se abandonem no horizonte os conhecimentos carregados, porque não representam excesso de bagagens nas elucubrações, mas carimbam, sem prazo de validade, o passaporte da emancipação.

\section{REFERÊNCIAS}

BITTENCOURT, S. As licitações públicas e o estatuto nacional das microempresas. Belo Horizonte: Editora Fórum, 2010.

BUCCI, M. P. D. Ed. Fundamentos para uma teoria jurídica das políticas públicas. São Paulo: Saraiva, 2013.

ESCOBAR, A. (1992): "Imagining a post-development era: Critical Thought, social movementes and development". Social Text $\mathbf{n}^{\mathbf{0}}$ 31/32, Special Issue on Third World and Postcolonial issues, Duque University Press. 1992. 
HEIDEMANN, F. G., SALM, J. F. Políticas Públicas e desenvolvimento: bases epistemológicas e modelos de análise. Brasília: Editora Universidade de Brasília, 2014.

HOChMan, G.; ARRetChe, M.; MARQUES, E. C. Políticas Públicas no Brasil. Rio de Janeiro: Fiocruz, 2007.

MARQUES, E. C. L; PIMENTA, C. A. A política pública como campo multidisciplinar. São Paulo: Editora Unesp, 2013.

NOGUEIRA, J. P; MESSARI, N. Ed. Teoria das Relações Internacionais: Correntes e Debates. Rio de Janeiro: Elsevier, 2005.

PINHEIRO, L; MILANI, C. R. S. Política Externa Brasileira: as práticas da política e a política das práticas. Rio de Janeiro: Editora FGV, 2012.

REALE, M. Filosofia e teoria política: ensaios. São Paulo: Saraiva, 2003.

SANTANA, J. E. Termo de Referência: o impacto da especificação do objeto e do termo de referência na eficácia das licitações e contratos. Belo Horizonte: Editora Fórum, 2015.

SILVA, C. L. Políticas Públicas e desenvolvimento local. Petrópolis: Editora Vozes, 2012.

SEN, A. K., Ed. Desarrollo y libertad. Barcelona: Editorial Planeta, 2000.

SUNDFELD, C. A. Direito administrativo para céticos. São Paulo: Malheiros Editores, 2014. Supremo Tribunal Federal (2007). Informativo $\mathrm{n}^{\mathbf{0}} 490$, disponível em: http://www.stf.jus.br/arquivo/informativo/documento/informativo490.htm\#ADI\%20e\%20Licita \%C3\%A7\%C3\%A3․ Último acesso em 22 de abril de 2016.

Tribunal de Contas da União (2008). Acórdão 1231, disponível em: https://contas.tcu.gov.br/juris/SvlHighLight?key=41434f5244414f2d4c454741444f2d373138313 3\&sort=RELEVANCIA\&ordem=DESC\&bases=ACORDAO-LEGADO;DECISAOLEGADO;RELACAO-LEGADO;ACORDAO-RELACAOLEGADO; \&highlight $=\&$ posicaoDocumento $=0 \&$ numDocumento $=1 \&$ totalDocumentos $=1$. Último acesso em 25 de setembro de 2016.

VAlle, V. R. L. Políticas públicas, direitos fundamentais e controle judicial. Belo Horizonte: Editora Fórum, 2009.

VILLAC, T. Direito internacional ambiental como fundamento principiológico e de Juridicidade para as Licitações sustentáveis no Brasil. In: SANTOS, M. G. Licitaçõos e contratações públicas sustentáveis. Belo Horizonte: Editora Fórum, 2015. 